\title{
Sexualidad, Género y Cultura en los estudios de comunicación audiovisual en España: el caso de GECA, Seminario Interuniversitario Permanente de Investigación
}

\author{
Francisco A. ZuRIAN HeRnáNDEZ \\ Universidad Complutense de Madrid \\ azurian@ucm.es \\ Miguel Borrego ERraZU \\ Universidad Complutense de Madrid \\ m.errazu@ucm.es
}

\begin{abstract}
Resumen
Los medios audiovisuales son un campo de producción cultural decisivo en la construcción de modelos de identidad de género en las sociedades contemporáneas. Para investigar estos procesos y estimular las transformaciones culturales por la igualdad y la diversidad se creó el Seminario Interuniversitario Permanente de Investigación "Género, Estética y Cultura Audiovisual" (GECA), vinculado al Departamento de Comunicación Audiovisual y Publicidad 1 y dentro del Grupo de Investigación de la UCM "Formación en Nuevas Tecnologías del Audiovisual" (FONTA). GECA es una red de investigación interuniversitaria, internacional e interdisciplinar cuyos intereses giran en torno a los estudios de género, feministas, de hombres, mujeres, masculinidades y estudios LGTBI y teoría Queer en relación, aunque no en exclusiva, con la cultura audiovisual española contemporánea. La actividad de GECA, en forma de workshops, seminarios, congresos, publicaciones y tesis doctorales, constituye un campo de acción investigadora novedoso y crucial en el ámbito de la universidad española y los estudios de comunicación, cuya consolidación debe servir de plataforma para futuras líneas de trabajo en relación con los estudios de género, culturales, de estética y cultura audiovisual.
\end{abstract}

Palabras clave: Cultura audiovisual; Estudios de género; Estética, Interdisciplinariedad; Igualdad.

Sexuality, Gender, and Culture in Spanish Audiovisual Communication Studies: the GECA Case, a Permanent Inter-University Research Seminar.

\begin{abstract}
Audiovisual media constitute a field of cultural production that plays a crucial role in the construction of gender identities in contemporary societies. In order to gain insight into these processes and encourage cultural transformations that might favour gender equality and diversity, we started the Permanent Inter-University Research Seminar "Género, Estética y Cultura Audiovisual" (GECA), currently at the Department of Audiovisual Communication and Advertising I (UCM) and under the UCM Research Group "Formación en Nuevas Tecnologías del Audiovisual" (FONTA). GECA is an inter-university, interdisciplinar and international web of research focused on Gender, Feminist, Men, Women, Masculinities, LGBTI and Queer studies, as may be used-but not solely - for the study of contemporary spanish audiovisual culture. GECA's activities - such as Workshops, seminars, publications or $\mathrm{PhD}$ Thesises - conform a new and crucial field of research within the spanish university and communication studies. Its consolidation should serve as a starting point for future lines of research related to the fields of aesthetics, audiovisual culture, gender and cultural studies.
\end{abstract}


Keywords: Audiovisual Culture; Gender Studies; Aesthetics; Interdisciplinarity; Equality.

Referencia normalizada:

Zurian Hernández, F. A. y Borrego Errazu, M. (2013) Sexualidad, Género y Cultura en los Estudios de Comunicación Audiovisual en España: el caso de GECA, Seminario Interuniversitario Permanente de Investigación. Historia y Comunicación Social. Vol. 18. Nº Especial Diciembre. Págs. 411-422.

Sumario: 1. Introducción. 2. Estudios de género en España. 3. GECA. 4. Líneas de investigación. 4.1. La construcción de discursos de género, sexualidad e identidad en el audiovisual español y su formulación desde los géneros cinematográficos. 4.2. Representación de (nuevas) masculinidades en el audiovisual contemporáneo. 4.3. Representaciones de masculinidades teens en el audiovisual español de ficción y su poder prescriptivo en la construcción del imaginario masculino en adolescentes y jóvenes. 4.4. Estéticas contemporáneas y nuevos discursos audiovisuales: la desaparición de fronteras, arte, industria y consumo. 5. Proyectos de investigación. 6. Actividades. 7. Publicaciones. 8. Conclusiones. 9. Bibliografía. 10. Notas.

\section{Introducción}

La constitución cultural de las sociedades contemporáneas está fuertemente influenciada por los medios audiovisuales. La representación, el intercambio, la producción y el consumo de significados culturales pasan ineludiblemente por estos, de tal modo que pueden considerarse tanto un reflejo como un motor activo de la sociedad en la que se insertan. Además, la transformación que el espacio del audiovisual viene sufriendo desde hace unos años, por la que a los procesos de convergencia medial debe también sumarse la multiplicación de formatos, dispositivos y pantallas, y las nuevas formas de consumo y producción que conllevan, posibilitan maneras de relacionarse con las imágenes cada vez más influyentes en la configuración de la identidad, la experiencia y la realidad social. Ofrecen por tanto un espacio de representación idóneo para conocer la imagen que una determinada sociedad se da a sí misma en cuestiones de género y sexualidad, pero también un espacio de mediación entre diferentes individuos y colectivos abierto a nuevas dinámicas y posibilidades de constitución de identidades. Por esta razón, los medios audiovisuales juegan un papel crucial en la transformación, la crítica y la visibilización de significados culturales e identidades no normativas o dominantes, tradicionalmente reprimidas u ocultadas.

\section{Estudios de género en España}

La relación entre los medios audiovisuales y los estudios de género es sin duda lejana. Desde el punto de vista de los fundamentos disciplinares de estos estudios en el ámbito universitario, se remonta al menos a las contribuciones de la teoría fílmica feminista de los años setenta en el ámbito anglosajón. Los enfoques de género han resultado especialmente fértiles primero con respecto al cine, luego a la televisión 
$\mathrm{y}$, en la actualidad, respecto a los diversos y variados modos de presentarse eso tan basto - y a veces tan vago - del «audiovisual», un cajón de sastre en el que podrían incluirse desde las estrategias de apropiación audiovisual en el ámbito del arte a las piezas de guerrilla accesibles en Internet o el consumo y diseminación viral de vídeo en red 2.0. Así, tanto desde la producción como desde el ámbito del estudio y el análisis, la relación entre audiovisual y género es cada día mayor y más fecunda. En este sentido, la "socialización" de Internet producida a lo largo de la última década, es decir, la explosión de la presencia del internauta como generador de contenidos y la presencia masiva de redes sociales, ha producido también una nueva confluencia de intereses que ponen en relación tecnología, dispositivos mediales, estudios culturales y procesos de construcción de identidades. Estas nuevas dinámicas espectatoriales y de consumo han servido también para legitimar estudios tradicionalmente periféricos, como los estudios pornográficos, como campos de investigación por derecho propio desde los que investigar las nuevas relaciones entre el cuerpo, la sexualidad y la identidad.

A pesar de que el marco epistemológico de los estudios de género ha sido tradicionalmente "extraño" en el ámbito de la universidad española pero, con todo, "el panorama ha cambiado mucho y se puede ya visualizar un interés creciente por los estudios de género en los departamentos de comunicación audiovisual en España" (Zurian, 2012: 9). Sin duda, cada vez existen más departamentos y grupos de investigación interesados en los estudios de género, identidad y sexualidad en el ámbito de la cultura audiovisual. Sin embargo, el hecho de que su influencia e importancia internacional haya crecido en los últimos años no significa que se hayan asentado plenamente en los departamentos universitarios españoles y, mucho menos, en sus planes de estudio. Para tratar de dar una respuesta y ahondar en todas estas cuestiones se creó el Seminario Interuniversitario Permanente de Investigación "Género, Estética y Cultura Audiovisual (GECA)" en 2008, fundado y dirigido por el profesor Francisco A. Zurian.

\section{GECA}

GECA nace de manera informal, como un seminario de profesores y estudiantes, en 2008 y, formalmente, en enero de 2010 en la Universidad Carlos III de Madrid, gracias a un proyecto financiado por el Instituto de la Mujer del Gobierno de España (Resolución del 13 de julio de 2009, "BOE" del 22 de julio). Gracias a un segundo proyecto del Instituto de la Mujer del Gobierno de España (Resolución del 30 de diciembre de 2010, "BOE" del 17 de febrero de 2011), GECA da un nuevo impulso bajo el nombre ya completo de Seminario Interuniversitario Permanente de Investigación "Género, Estética y Cultura Audiovisual (GECA)" y se sitúa en el Departamento de Comunicación Audiovisual y Publicidad-1 de la Universidad Complutense de Madrid (UCM). 
GECA desarrolla su labor de investigación en el campo de los estudios culturales y de género, con capacidad para proponer resultados al debate social, cultural y político. Esta red de investigación, interuniversitaria, internacional e interdisciplinar, está constituida por investigadoras e investigadores pertenecientes a más de diez universidades españolas y veinte extranjeras, que comparten un interés por cuestiones relacionadas con los estudios de género (Gender Studies), feministas, de mujeres (Women Studies), de hombres y masculinidades (Men Studies), de diversidad afectivo-sexual, estudios LGBTI y teoría Queer así como con los estudios culturales (Cultural Studies). Estos enfoques están orientados al estudio de la cultura audiovisual (con especial énfasis en la española contemporánea) y siempre en interrelación con las respectivas áreas y disciplinas de cada miembro de la red, que comparten una marcada perspectiva estética y teórica. De hecho, GECA engloba entre sus investigadores e investigadoras a académicas y académicos provenientes de diferentes campos disciplinares (no solamente relacionados con la Comunicación Audiovisual sino también con la Publicidad, el Periodismo, la Filosofía, Sociología, Arte, Literatura, Historia, el Hispanismo, etc.), ya que el estudio y el análisis de la cultura audiovisual en la actualidad debe afrontarse necesariamente a partir de la confluencia de diferentes disciplinas académicas que den cuenta de la enorme complejidad de la cultura audiovisual contemporánea.

Por tanto, la red de GECA permite organizar y construir un espacio colaborativo, de encuentro, intercambio y organización permanente de actividades de investigación, transferencia y divulgación del conocimiento en el ámbito universitario puesto al servicio de toda la sociedad. Las actividades desarrolladas por GECA, detalladas a continuación, son un ejemplo de cómo la investigación académica puede servir como impulsor para la consecución en la práctica de políticas no discriminatorias y de igualdad de género en el ámbito de la ciencia e investigación, del trabajo y del estudio. Así, la riqueza de enfoques diferentes y la creación de sinergias y espacios de discusión que favorece GECA hace más sencilla la transferencia de conocimiento desde el ámbito estrictamente universitario al conjunto de la sociedad.

\section{Líneas de investigación}

GECA mantiene abiertas diferentes líneas de investigación, cuya variedad es una de sus características más distintivas. Sus resultados son visibles en forma de publicaciones, ponencias, workshops y tesis doctorales desarrolladas por investigadores jóvenes. Bajo el paraguas de GECA, muchos investigadores e investigadoras están desarrollando estas líneas de trabajo y colaborando en la consolidación, de este modo, de los estudios de género en el ámbito de la comunicación audiovisual en la universidad española desde la Universidad Complutense de Madrid. Las líneas fundamentales de investigación que se desarrollan en la actualidad, junto a los doctorandos y doctorandas que las desarrollan en GECA, son las siguientes: 
4.1 La construcción de discursos de género, sexualidad e identidad en el audiovisual español y su formulación desde los géneros cinematográficos.

Desde su constitución como campo de estudio por derecho propio, los estudios feministas han recalcado la estrecha relación entre el discurso audiovisual y la construcción de las identidades de género. La tesis doctoral de Beatriz Herrero Jiménez, La construcción de la identidad femenina en el entramado de los géneros cinematográficos que componen los Woman's Film escritos y dirigidos por Isabel Coixet, pretende, partiendo del análisis de los códigos y convenciones del género cinematográfico de los Women Films y aplicando el entramado de las Teorías Fílmicas Feministas anglosajonas, estudiar las representaciones de género, concretamente sobre las mujeres, que la cineasta española pone en escena. Por otro lado, David Asenjo Conde adopta un enfoque más histórico para revisar, en su tesis doctoral Atisbando la intersexualidad en el cine tardofranquista: las representaciones de la identidad sexual en Mi querida señorita (1971) de Jaime de Armiñán, los vínculos estéticos y discursivos en los que se sustenta la concepción y recepción del filme de Armiñan hasta nuestros días, como un ejemplo paradigmático y pionero en el cine español de una representación de la identidad sexual ambigua alejada de estereotipos y comprometida con una representación seria y humanista de la identidad intersexual.

4.2 La representación de (nuevas) masculinidades en el audiovisual contemporáneo.

Uno de los campos de estudio más contemporáneos y urgentes del audiovisual contemporáneo es la exploración de modelos de masculinidad que contesten, cuestionen o abran alternativas incluyentes a la representación del hombre tal y como ha funcionado de manera dominante a lo largo de la historia del cine. Antonio A. Caballero Gálvez, en su tesis doctoral La representación de la(s) masculinidad(es) en el videoarte español (2000-2010) (defendida en 2012), toma como objeto de estudio la tradición del videoarte en España como espacio de creación audiovisual especialmente relevante para encontrar una articulación de la masculinidad alejada de los discursos y modos de representación dominantes. Así, toma como base la epistemología surgida de la Teoría Queer y los Estudios sobre Masculinidades, para desarrollar un análisis audiovisual y hermenéutico del videoarte realizado en la primera década del siglo XXI dentro del Estado Español, cuya temática vertebradora sea el cuestionamiento de la masculinidad hegemónica y/o dar visibilidad a masculinidades subversivas a través de la representación del cuerpo. Si el acercamiento a otros formatos y medios de expresión audiovisual es la estrategia adoptada por Caballero Gálvez, el trabajo de investigación doctoral de Víctor Rivera Perdomo, La noción de violencia y representación de masculinidad en el cine de Sergio Cabrera, toma por objeto la producción cinematográfica del director colombiano como paradigma de una crítica social amparada en las relaciones entre la violencia cotidiana de la sociedad colombiana y los modelos de masculinidad propios del discurso patriarcal que Cabrera pone en escena. 
4.3 Representaciones de masculinidades teens en el audiovisual español de ficción y su poder prescriptivo en la construcción del imaginario masculino en adolescentes y jóvenes

Si bien el cine o el audiovisual de artistas son espacios de sumo interés para investigar las posibilidades de modelos de construcción de identidades no hegemónicas, los medios audiovisuales dominantes, como la televisión, ofrecen también un campo de estudios fundamental para entender cuál es la imagen que la cultura dominante ofrece a la sociedad en cuestiones relacionadas con la sexualidad y la identidad de género. La tesis doctoral de Javier García, Representaciones masculinas en los personajes LGBTIQ en las series de ficción españolas, toma como objeto la producción de series de ficción televisiva nacionales para explorar las estrategias de representación de identidad LGTBIQ en un contexto de producción de decisiva influencia en la construcción del imaginario masculino contemporáneo, especialmente en el el entorno adolescente.

4.4 Estéticas contemporáneas y nuevos discursos audiovisuales: la desaparición de fronteras, arte, industria y consumo.

Por último, el estudio del audiovisual contemporáneo en todas sus manifestaciones y formatos posibilita afrontar una rica y compleja confluencia de discursos sobre la imagen que sea capaz de articular las distintas disciplinas tradicionales alrededor de un nuevo objeto de estudio decididamente en construcción. Los estudios feministas y de género no sólo han aportado herramientas fundamentales para las reivindicaciones históricas del feminismo y las identidades LGBTIQ, sino que su riqueza conceptual es decisiva también para entender las transformaciones culturales y simbólicas en las esferas de la representación, la estética y la política. Miguel Borrego Errazu, en su tesis doctoral Políticas del índice. Estética y teoría de la indexicaliad en el cine y la cultura digital (defendida en 2013) examina el concepto semiótico del índice, tradicionalmente asociado a las teorías clásicas del cine, como una herramienta que debe ser pensada junto a la evolución de las diferentes versiones de los estudios feministas del cine y que alcanza una importancia decisiva en las políticas de subjetivación contemporáneas construidas en torno al espacio relacional de internet.

Las diferentes líneas de investigación que desarrollan los doctorandos de GECA ponen de relieve la necesaria confluencia de estudios de corte más historiográfico con enfoques más teóricos y de análisis audiovisual. Los estudios de género, identidad y sexualidad, desde la perspectiva de GECA, no son únicamente un conjunto de herramientas que deben servir para visibilizar identidades invisibilizadas desde las estructuras de representación hegemónicas, sino que deben considerarse centrales en el desarrollo de una investigación en estudios culturales y visuales de todo tipo, e integrarse con normalidad en la vida universitaria española. Esta acción empieza a ser posible gracias a los proyectos de investigación que ha desarrollado GECA en sus cinco años de actividad. 


\section{Proyectos de investigación}

Desde el año 2008, y gracias a la colaboración de diferentes instituciones públicas y privadas españolas, GECA ha podido llevar a cabo un considerable número de proyectos de investigación específicos, que han servido de plataforma de lanzamiento tanto para nuevos investigadores e investigadoras como para afianzar la red de trabajo de GECA. Los proyectos de investigación realizados hasta la fecha por GECA son los siguientes:

1. "Representaciones de (nuevas) masculinidades por la igualdad", Instituto de la Mujer, Ministerio de Sanidad, Política Social e Igualdad, 2012-2013, IP: Francisco A. Zurian.

2. "Mujer y cine: la construcción de la propia imagen", Instituto de la Mujer, Ministerio de Sanidad, Política Social e Igualdad, 2012-2013, IP: Francisco A. Zurian.

3. "Salud y sus implicaciones de género y en la cultura audiovisual", Instituto de la Mujer, Ministerio de Sanidad, Política Social e Igualdad, 2011-2012, IP: Francisco A. Zurian.

4. "Los discursos detrás de la imagen: Mujer y Cine", Instituto de la Mujer, Ministerio de Sanidad, Política Social e Igualdad, 2011-2012, IP: Francisco A. Zurian.

5. "Representación del cuerpo e identidad de género", Instituto de la Mujer, Ministerio de Sanidad, Política Social e Igualdad, 2010-2011, IP: Francisco A. Zurian.

6. "La recuperación de las aportaciones hechas por las mujeres al cine español: los años 90", Instituto de la Mujer, Ministerio de Sanidad, Política Social e Igualdad, 2010-2011, IP: Francisco A. Zurian y Ubaldo Cuesta.

7. "Metáfora y metonimia en la construcción de identidades LGTB", Plan Nacional de Investigación del Ministerio de Ciencia e Innovación 2009-2013, IP: Prof. Dr. Alberto Bustos.

8. “Género, Estética y Representación Audiovisual”, Instituto de la Mujer, Ministerio de Igualdad, 2009-2010, IP: Francisco A. Zurian.

9. "La recuperación de las aportaciones hechas por las mujeres al cine español: de los orígenes del cine español a los años 80", Instituto de la Mujer, Ministerio de Igualdad, 2009-2010, IP: Francisco A. Zurian y Ubaldo Cuesta.

10. "Género, Estética y Representación Audiovisual", Programa Propio de Investigación de la Universidad Carlos III de Madrid, 2009-2010, IP: Francisco A. Zurian.

11. "Estética y género en el audiovisual contemporáneo", Programa Propio de Investigación de la Universidad Complutense de Madrid y Fundación General 
de la Universidad Complutense de Madrid, 2008-2009, IP: Ubaldo Cuesta y Francisco A. Zurian.

12. "Modelos de representación de diversidad afectiva-sexual y masculinidades en el cine español contemporáneo", Fundación Triángulo, 2008-2009, IP: Francisco A. Zurian.

13. "La representación de la mujer en el cine español dirigido por mujeres: algunos casos de estudio", Fundación Mare Nostrum, 2008-2009, IP: Francisco A. Zurian.

\section{Actividades}

La labor de investigación de GECA se centra también en actividades de investigación, principalmente en los encuentros de investigadores para poner en común sus avances, trabajos y líneas de investigación. En este sentido GECA organiza todos los años un Workshop Internacional de Investigación y, mensualmente, unos encuentros de investigadores, los Colloquium Series. De este modo se fomenta el contacto entre investigadores internacionales y españoles y la difusión de los resultados de sus investigaciones.

El I Workshop Internacional de Investigación organizado por GECA tuvo lugar los días 26, 27 y 28 de mayo de 2010, en la Universidad Carlos III de Madrid. Bajo la propuesta marco de "Género, Estética y Representación Audiovisual", significó la presentación pública de GECA y la primera actividad de investigación que organizaba con investigadores nacional e internacionales.

El II Workshop Internacional, celebrado los días 9 y 10 de Mayo de 2011 en la Facultad de Ciencias de la Información de la Universidad Complutense de Madrid, giró en torno a la "Representación del cuerpo e identidad de género en la cultura audiovisual contemporánea". Los textos y resultados expuestos durante este Workshop giraron en torno a las posibilidades de expresión y representación de identidades de género y corporalidad en lugares ajenos a los medios hegemónicos de representación cultural. A lo largo de este segundo encentro internacional se analizó parte de la producción audiovisual más reciente, con especial énfasis en las producciones españolas desde la Transición a nuestros días a fin de debatir el posible calado (o no) de los progresos sociales, culturales y políticos que se han dado en España a partir de leyes innovadoras como la de Igualdad, violencia de género, o la reforma del código civil sobre matrimonio e identidad de género.

El III Workshop Internacional, que tuvo lugar los días 7, 8 y 9 de Mato de 2012 también en la Facultad de Ciencias de la Información de la UCM, pivotó en torno a la "Representación del cuerpo dañado" en la cultura audiovisual contemporánea. A lo largo de este Workshop se debatió alrededor del cuerpo como "texto", es decir, como construcción social, cultural y filosófica, incidiendo en su dimensión performativa 
como un modo de cuestionar su apropiación completa por parte del orden simbólico. Este Workshop giró, por tanto, alrededor del papel de los medios audiovisuales en la construcción y representación de esta dimensión de la corporalidad, y abordó las capacidades subversivas y críticas de las diferentes cinematografías nacionales y extranjeras y su puesta en contraste con las diferentes relaciones de poder que se instituyen en cada contexto social. Este III Workshop Internacional de GECA sirvió asimismo como homenaje presencial para dos personalidades decisivas en el mundo de los estudios de género y la cinematografía española de mujeres respectivamente, Teresa de Lauretis y Josefina Molina. La Profa. Dra. Teresa de Lauretis, actualmente Emerita Professor de la University of California Santa Cruz (USA), realizó una conferencia plenaria que llevó por título "Panteridad: vivir en un cuerpo dañado"; la laudatio a su obra fue dictada por la Profa. Dra. Giulia Colaizzi (Universitat de València), que con su Feminismo y teoría filmica (Colaizzi, 1995), marcó un hito en los estudios de género aplicados al campo del audiovisual en el ámbito universitario español. El discurso de Josefina Molina fue precedido, así mismo, de una laudatio a cargo del Prof. Dr. Román Gubern (Catedrático Emérito, Universitat Autònoma de Barcelona).

El IV Workshop Internacional de GECA, que tuvo lugar los días 15 y 16 de Abril de 2013 en la Facultad de Ciencias de la Información de la UCM, giró en torno a la "Representación de (nuevas) masculinidades" en el audiovisual español contemporáneo. Este último Workshop estuvo enfocado hacia cuestiones relacionadas con la representación audiovisual de las (nuevas) masculinidades y su corporalidad, desarrollo y formación, así como su implicación con la lucha contra la violencia machista, su erradicación y las políticas de formación y concienciación que construyan una mentalidad (y políticas) en favor de la igualdad. Para ello, atendió especialmente a la construcción de nuevos tipos de masculinidades no machistas que pueden (y, de hecho, deben) propiciar estos objetivos de lucha contra la violencia de género y ser pro activos en la construcción de la igualdad efectiva (y no solamente jurídica) entre mujeres y hombres. Este IV Workshop Internacional de Investigación también contó con una sección miscelánea para propuestas especialmente relevantes que no se adecuaban completamente al monográfico propuesto, así como una sesión especial de homenaje académico que GECA rindió al profesor británico Paul Julian Smith, anteriormente catedrático de la University of Cambridge y, actualmente, Distinguished Professor del Graduate Center de la City University of New York (CUNY), cuya laudatio fue dictada por el profesor Román Gubern, catedrático emérito de la Universitat Autónoma de Barcelona. En abril de 2014 se desarrollará el V Workshop Internacional de Investigación bajo el título "Representaciones de género, violencia y educación en el reto del siglo XXI por la igualdad".

Por el lado de la transferencia del conocimiento y, también, la difusión de los resultados de la investigación así como la divulgación científica, GECA organiza Jornadas, Cursos, Conferencias y Encuentros que permiten el enriquecimiento de la sociedad con los resultados de su trabajo de investigación. Así se organizan todos los años las Jornadas de Mujer y Cine1, el Curso "Una mirada arcoíris"2, así como 
encuentros y conferencias con ONGs, fundaciones, asociaciones, festivales, como, por ejemplo, CIMA (Asociación de mujeres cineastas y de los medios audiovisuales), La Fundación Autor (y SGAE), AUVIM (Asociación Universitaria contra la violencia machista), la Federación Estatal de Lesbianas, Gais, Transexuales y Bisexuales (FELGTB), la Fundación Triángulo y su festival de cine LesGaiCineMad, etc. ${ }^{3}$

\section{Publicaciones}

La actividad investigadora desarrollada por GECA ha permitido, asimismo, la publicación de diferentes textos en forma de libros editados y coordinación de revistas especializadas. Así, en el año 2011 aparecieron los volúmenes Imágenes del Eros. Género, sexualidad, estética y cultura audiovisual (Zurian (ed.), 2011) y Pensar el cine (Zurian, 2011). Fruto de los encuentros, Colloquium Series y Workshops Internacionales organizados por GECA, así como de los proyectos de investigación desarrollados por GECA, Imágenes de Eros aglutina algunos de los trabajos más sobresalientes presentados en el marco de estas actividades, y seleccionados por el Comité Científico Internacional de GECA ${ }^{4}$. Este volumen, reflejo de la actividad investigadora de GECA, pone en conexión el trabajo de investigadores consagrados a nivel nacional e internacional (Teresa de Lauretis, Jean-Claude Seguin, Paul Julian Smith, Dieter Ingenschay, Josetxo Cerdán, María Luisa Ortega o el propio Francisco Zurian, por citar algunos) con jóvenes investigadoras e investigadores que están desarrollando su trabajo doctoral en el marco de GECA (como Beatriz Herrero o Antonio Caballero).

Por otra parte, Pensar el cine (Zurian, 2011) recoge el interés por cuestiones relacionadas con la estética y la teoría del cine a partir de la obra del filósofo y teórico francés del cine Henry Agel, en un movimiento que habla de la necesidad de no abandonar la investigación más "teórica" en el campo de la estética audiovisual.

El número 34 de la revista Secuencias (2 ${ }^{\circ}$ semestre 2011, publicado en 2012), coordinado por el Prof. Dr. Zurian, estuvo consagrado al campo de la "Sexualidad y políticas de género en el audiovisual", construyéndose así como una muestra más de la fertilidad de la producción investigadora de GECA. Los textos que componen este número están firmados por Alberto Mira (Oxford Brookes University), Dieter Ingenschay (Humboldt Universität zu Berlin), Beatriz Herrero (GECA) y Francisco A. Zurian, continuando con la política de conjugación de investigadoras más junior con otros ya más consagrados.

\section{Conclusiones}

Desde su constitución en 2008, la labor emprendida por GECA ha cristalizado en un elevado número de proyectos de investigación cuyos frutos pueden observarse 
en diferentes publicaciones, tesis doctorales (ya defendidas tres de ellas) y actividades de investigación, transferencia y divulgación del conocimiento. Todas estas líneas de trabajo muestran de qué modo la propuesta de GECA, construida sobre la colaboración interdisciplinar, interuniversitaria e internacional alrededor de la cultura audiovisual y las cuestiones de género e identidad sexual, ha cristalizado en acciones que son, en el ámbito de la Universidad española, un caso especialmente singular. En este sentido, la red de investigación tejida por GECA es un ejemplo de dedicación, esfuerzo y voluntad de visibilización, tanto en el ámbito estrictamente académico como en el conjunto de la sociedad y las instituciones e industrias culturales, de un rico y decisivo conjunto de cuestiones cuya urgencia, en la actualidad, exige el compromiso de cada vez un mayor número de investigadores e investigadoras del audiovisual.

Si bien los estudios de género no han formado parte integrante de la tradición académica española en el campo de la comunicación audiovisual, casos como el de GECA (y tantos otros) apuntan a su definitiva consolidación en las facultades de Comunicación españolas mostrando la fecundidad de los estudios de género aplicados al audiovisual y la comunicación. GECA ofrece un espacio colaborativo para que, cada investigadora y cada investigador, desde sus propias posiciones, intereses, grupos de trabajo, etc., realicemos un esfuerzo de visibilización de nuestras investigaciones.

\section{Bibliografía}

COLAIZZI, Giulia (Ed.) (1995): Feminismo y teoría filmica. Episteme. Valencia. ZURIAN HERNÁNDEZ, Francisco A. (Ed.) (2011): Imágenes del Eros. Género, sexualidad, estética y cultura audiovisual. Ocho y medio libros de cine. Madrid.

ZURIAN HERNÁNDEZ, Francisco A. (2011): Pensar el cine. En torno a la teoría estética de Henri Agel. Ocho y medio libros de cine. Madrid.

ZURIAN HERNÁNDEZ, Francisco A. (Coord.) (2012): Sexualidad y políticas de género en el audiovisual en Secuencias Revista de Historia del Cine. $2^{\circ}$ semestre de 2011, Maia Ediciones y Publicaciones de la Universidad Autónoma de Madrid. Madrid.

ZURIAN HERNÁNDEZ, Francisco A. (Ed.) (2013): Cuerpos filmados. Representaciones del cuerpo en la cultura audiovisual. Ocho y medio libros de cine. Madrid. (en prensa, fecha prevista diciembre 2013)

ZURIAN HERNÁNDEZ, Francisco A. (Ed.): Construyendo la propia mirada: mujeres directoras en el cine español (de los orígenes al año 2000). Editorial Síntesis. Madrid. (en prensa, fecha prevista enero 2014)

ZURIAN HERNÁNDEZ, Francisco A. (Ed.): Hombres filmados. Masculinidades y cultura audiovisual. Editorial Síntesis. Madrid. (en prensa, fecha prevista enero 2014) 


\section{Notas}

12 Jornadas de "Mujer y cine: La construcción de la propia imagen", Universidad Complutense de Madrid, del 4 al 13 de marzo de 2013. I Jornadas de "Mujer y cine: los discursos detrás de la imagen", Universidad Complutense de Madrid, abril y mayo de 2012. Ambas Jornadas propiciadas gracias a la colaboración de GECA con CIMA (Asociación de Mujeres Cineastas), la Fundación Autor-SGAE, la Universidad Complutense de Madrid, y la ayuda del Instituto de la Mujer y el Fondo Social Europeo.

2 Curso especializado "Una mirada Arcoíris. Comunicación y comunicación LGBTIQ”, Universidad Complutense de Madrid, del 2 al 5 de abril de 2013.

3 En este sentido, cabe destacar los seminarios dedicados a las mujeres directoras en el cine español, de los que se han celebrado ya dos encuentros: II Seminario "Mujeres directoras en el cine español de los años 90. La recuperación de las aportaciones hechas por las mujeres al cine español”, Universidad Complutense de Madrid, 11 y 12 de mayo de 2011. Y I Seminario. "Mujeres directoras en el cine español desde los orígenes a los años 80 . La recuperación de las aportaciones hechas por las mujeres al cine español”, Universidad Complutense de Madrid, 24 y 25 de mayo de 2010.

4 El Comité Científico de GECA se compone de los siguientes miembros: Presidentas de Honor: Josefina Molina, Teresa de Lauretis (University of California, Santa Cruz, USA). Director: Francisco A. Zurian (Universidad Complutense de Madrid). Vocales: José María Álvarez Monzoncillo (Universidad Rey Juan Carlos); Ana Amado (Universidad de Buenos Aires, Argentina); Nancy Berthier, Université de Paris-IV-Sorbonne; Enrique Bustamante, Universidad Complutense de Madrid; Giulia Colaizzi, Universitat de València; Brad Epps, Harvard University (USA); Uta Felten, Universität Leipzig (Alemania); Rosa Franquet, Universidad Autónoma de Barcelona; Emilio García, Universidad Complutense de Madrid; Francisco García, Universidad Complutense de Madrid; Julio César González Pagés, Universidad de La Habana (Cuba); Román Gubern, Universidad Autónoma de Barcelona; Dieter Ingenschay, Humboldt Universität zu Berlin (Alemania); Jo Labanyi, New York University (USA); Margarita Ledo Andión, Universidade de Santiago de Compostela; Denilson Lopes, Universidade Federal do Rio de Janeiro (Brasil); Alfredo Martínez Expósito, University of Melbourne (Australia); Alberto Medina, Columbia University (USA); Manuel Palacio Arranz, Universidad Carlos III de Madrid; Christopher Perrian, University of Manchester (Reino Unido); Jean-Claude Seguin, Université Lumière-Lyon 2 (Francia); Alison Sinclair, University of Cambridge (Reino Unido); Paul Julian Smith, City University of New York (USA).

\section{Los autores}

Francico A. Zurián Hernández es director del Seminario Interuniversitario Permanente de Investigación "Género, Estética y Cultura Audiovisual (GECA)" de la Universidad Complutense de Madrid y es profesor de dicha Universidad.

Miguel Borrego Errazu es investigador de GECA y profesor de la Universidad Complutense de Madrid 